\title{
A Review of Research Concerning Lighting in Manufacturing Plants
}

\author{
Siti Hajar Mohd Yusop ${ }^{1,}$, Ismail Nasiruddin Ahmad ${ }^{1, \mathrm{~b}}$, \\ Muhammad Izzat Nor Ma'arof. ${ }^{1, c}$
}

\author{
${ }^{1}$ Faculty of Mechanical Engineering, Universiti Teknologi Mara 40450 Shah Alam, Selangor, \\ Malaysia \\ asiti_hajar287@yahoo.com, biahmad886@gmail.com, 'cmuhammad.izzat87@gmail.com
}

Keywords: Lighting, manufacturing, automotive, visual capability, eye strain, lux meter

\begin{abstract}
Based on the Market Watch 2012 with regards to the ASEAN region, Malaysia is the third biggest automotive manufacturing nation which employs more than 300,000 people. To accomplish their operation demands, manufacturing companies such as Proton and Perodua would utilize artificial lighting in their respective manufacturing plants. Research on the effects of artificial lighting on human expended about millions of dollars every years. Sufficient lighting is required for effective tasks completion while providing adequate visual capability, thus will ensure the safety of the operators. Eye strain, migraine and headache are among the common symptoms caused by poor lighting at workplace. This study aims to review on prior research regarding sufficient lighting while giving a special focus on light assessment techniques and tools in determining the luminous level in manufacturing plants. This study will contribute to create awareness among the manufacturing plant on the importance of lighting in term of work performance and occupational safety and health.
\end{abstract}

\section{Introduction}

The eye is the human organ which converts light into nerve impulses which later transmitted to the brain, thus, translated into visual images [1]. Although light is the key in enabling human to have visual information, yet, it is also influential in causing visual discomforts which eventually leads to other psychophysical discomforts. In addition, sources of lights also have a significance impact to the work output of the operator especially in terms of productivity rate regardless of their age [2]. This study aims to review literature regarding sufficient lighting in the manufacturing industries while giving a special focus on light assessment techniques and tools in determining the luminous level in the manufacturing plants. The objective is to generate higher level of awareness among manufacturing plants on sufficient lighting since it is related to both workers' performance and safety.

\section{Sufficient Lighting}

Visual issues such as eye strain, migraine and headaches among operators had become one of the major issues focused in the manufacturing industries by ergonomists and managements alike. Health and Safety Executive (HSE) stated that insufficient lighting at the workplace could represent a significant cost to the company in the form of time off work as a result of accidents and injuries, increased absenteeism and reduced staff efficiency and productivity [3].

In addition, HSE emphasized that symptoms like eye strain, migraine and headaches are the common symptoms associated with poor lighting condition at the workplace [3]. This study suggested that poor lighting condition would leads to visual limitation among employees, thus, making them prone to accidents and injuries. This would ultimately affect the productivity and overall profit made by the company due to the shortage of employees and also the increase in medical expenses.

There are a number of interpretations in the literature in defining the working condition denoted as 'insufficient lighting'. Wolska noted that occurrence of insufficient lighting when the operators would experience "glare" and "flicker" [4]. The study defined "glare" as a phenomenon which 
exists when parts of visual field are excessively bright in relation to the brightness of the general surrounding to which the eyes are adapted [4]. The study further noted that "glare" is divided into two types which are "disability glare" and "discomfort glare" [4]. "Disability glare" is defined as the condition when a large source of low luminance or small source of high luminance is seen close to the line of sight to the visual tasks is defined of disability glare; while "discomfort glare" is noted as the feeling of discomfort, annoyance and irritation without necessarily impairing the vision of details or objects [4].

According to International Commission on Illuminance Standard (CIE 2001), impression of unsteadiness of visual sensation induced by a light stimulus whose luminance or spectral distribution fluctuation over time is called "flicker" [4]. Flicker usually causes distraction, headache or various visual complaints [4]. Flicker usually increases with the lamp's age (especially for fluorescent lamps) [4].

Boyce stated that "shadows" and "veiling reflections" are another two lighting conditions which could also causes physiological discomfort among operators [5]. Shadows occurred when light is intercepted by an opaque object, for instances, a large piece of machinery; hence, casting a shadow in the adjacent areas [5]. Veiling reflection is the condition when a source of high luminance light (for example, a luminaire or a window) is reflected from a specularly reflecting surface such as a glossy printed page or a computer screen [5]. All of these working conditions should be avoided to allow the operators to work in a comfortable working condition while simultaneously maintaining physical health and well-being.

\section{Manufacturing Issues}

Several issues occur in manufacturing plants regarding lighting. This statement is supported by Untimanon et al., reported that increasing the level of illumination of the light as practiced among electronics and jewelry industries in Thailand could aid in solving visual issues among employees [6]. The study emphasized that by increasing the lighting illumination and also by introducing short rest interval to avoid visual fatigue with increasing visual loading; visual issues reduce from $48.3 \%$ to $24.5 \%$ (reduction of $23.8 \%$ ) [6]. Nevertheless, it was still reported that 20 out of 290 operators would still feel uncomfortable with increment in illumination [6].

This finding by Untimanon [6] is supported by Fischer [7] who documented that there is no specific level of illumination which could satisfy everyone, though, generally, the optimum level of illumination is approximately 2000 lux. Thus, this study concluded that different individual has different comfort level or opinions with regards to sufficient lighting in their workplace.

Based on the factory lighting in the war-time era, reported that lighting was one of the important aspects that had been considered [8]. To prevent eye strain, facilitate accuracy and promote safety, sodium lighting was installed [8]. In addition, electrical energy consumption by lighting was regulated due to its contribution in term of overall cost to the manufacturing plants [8].

Connolly emphasized that lighting is very important in any industries which involve visual accuracy, for instances, the inspection process [9]. The study noted that the selection of light sources and its positioning are two major aspects which should be considered during lighting installation [9]. This research is supported by Steemers' who noted that illuminance levels required on a work surface depend on the visual difficulty of the tasks had been carried out [10].

From the observation of this study, the selection of lighting illuminance is very important. Proper lighting installation and illuminance level would assist the operators to perform their tasks. Based on all these findings, this study would like to highlight on the importance of lighting in the industry and it was observed that lighting issues had shown improvement from times to times.

\section{Luminous and Assessment of Lighting}

Hwang and Kim defined 'luminance', L (unit: cdm-2 candelas per unit square metre) as the physical measure of brightness [11]. It represents the luminous intensity emitted (or reflected) in a given direction per projected area of a luminous (or reflecting) surface [11]. Adaptation level of 
eyes which affects task visibility and visual comfort controls by the luminance distribution in the field of view controls [11]. Excessively low luminance ratio generally results in a dull and nonsimulating environment while excessively high luminous ratios could causes fatigue or glare [11].

Different in luminance will caused by different reflectance depends on the illuminance to perform visual tasks [11]. Illuminance is the luminous flux/ unit area at a point on a surface (Lumens/m2) [12]. Luminous flux by Halendar or luminous power [13] (unit: 1m, lumen), a quantity derived from radiant flux or "radiant power" [13] (in watts, W) by evaluating the radiant according to the spectral sensitivity of the human eye (as defined by the CIE standard photometric observer) [11]. The angular density of the luminous flux in a given direction is called luminous intensity, I (unit: cd, candela) [11]. Luminous intensity is luminous flux emitted in a very narrow cone containing the given direction divided by the solid angle of the cone, i.e. luminous flux/ unit angle solid angle (Candela, cd) [12].

This study would like to highlight that it was reported in previous literature that the level of luminous is important in term of producing a good lighting condition for the workers especially in the manufacturing plant. It was reported that lighting level condition should be according to the specification that is provided by the requirement according to specification of tasks [9, 10]. Every task facilitate by illumination provided to ensure consideration of the comfort for the operators [12].

The luminous level of lighting in buildings could be assessed or measured in a number of ways using different types of tools. In the year 1975, the lighting had been measured by using photometer at airport as stated by McCloy [14]. National Physical Laboratory verified every photometer calibration against a standard test lamp and noted that the equipment ensures accurate readings with the clear marking of the scale on the meter together with a knife-edge pointer [14].

This study is supported by Halendar who acknowledged that a device used to measure luminance is called photometer [13]. For the measurement of illuminance, the photometer may be placed at any positions and then being pointed towards the luminance surface at a convenient distance for the data to be obtained. Another method is to place the meter on the surface of the light source and the reading on the display is observed [13].

Hyzer made a research on accident investigation by using Extinction-Type Photometering Technique for low-light-level luminance measurement [15]. In that investigation, luminance meter had been used to measure the luminance in more direct and credible methods [15]. Illuminance is measure by using Minolta Illuminance Meter T-1 which is capable of measuring down to 0.01 lux [15]. In that research, it was concluded that this method is unsuitable to be used under good lighting condition where the higher contrast is difficult to obtain between the source and the background [15].

In the manufacturing assembly and inspection line, this method is not suitable due to limitation of the light level contrast. This study has the opinion that using this particular device is perhaps suitable for locations such as within the inventory section or the storage room. Inventory section usually dimly lighted because it is not always being actively used in contrast with other sections such as the assembly lines.

On September 2002, Putrajaya Lighting Masterplan conducted (cosine corrected) illuminance (ELux) meter to measure illuminance on the surface of the road [16]. This equipment described more accurate reading on the road perception in term of brightness and visualization for a motorist [16]. To ensure accuracy of this equipment, for instances being affected with stray shadows; the measurement was conducted very carefully [16]. Hence, this study would like to emphasize that illuminance measuring equipment should be handle with care and being operated in accordance to its standard operating procedure (SOP) for accurate data collection could be gathered.

Hwang and Kim utilized the Digital Light Meter and a two-dimensional Colour Analyser to measure the luminance of the window [11]. There are three model facilities that had been carried out which is for illuminance measurement, Topcon IM-5 and Lutron YK-2005LX and Minolta CA2000A for luminance measurement [11]. The study emphasizes on the occupants and eye health in which the measurement of the windows where conducted five times in three test spaces $(10 \mathrm{~F}, 20 \mathrm{~F}$ and 30F) [11]. 
In addition, this study would like to give a special focus on the usage of Lux Meter in performing similar task. A lux meter is an electronic measurement for physical and chemical value [17]. The illumination level at the worksite of each worker was measured using a lux meter (Model Testo 545) [6]. The function of Lux Meter used for measuring light in the workplace and others [17]. Lux is measuring unit for light intensity [18]. Lux meter has many advantages such as gives fast response of the data from the surrounding, it can be held using hand and cam be placed according to requirement, and the best advantages of this equipment is easy to operate while conducting the experiment [18].

In order to have a good light quality for workplaces, lux meter is one of the tools which can measure efficiently and easily [17]. Lux meter can provide convenient data analysis by using Comfort Software which is the data can be read out and location list can be saved [17]. A special optical filter has been provided in the lux meter [17]. It is possible to carry out accurate measurements on different light sources which may vary in color [17]. This shows lux meter has many advantages and already be used by several researchers in their respective studies.

The usage of the lux meter is supported by Chan et al. measure living room during daytime on the selected area. In addition, outdoor lux level on the roof and podium was taken from the indoor/outdoor lux level ratio also by using lux meter [19]. This study reported that the average illuminance level in the room is 181 lux level fell far below the recommended of 500 lux for study purpose. Furniture layout and room partition can obstruct sunlight penetration into the room [19]. The result is come out with recommendations to use artificial lighting when reading or at work [19]. Compare due to high level at the outdoor environment, light average of 47500 lux may cause discomfort cause by glare [19]. This study emphasized that glare should be critically avoided due to its adverse effect on human health. Sufficient lighting can be obtained in a room by considering the factors such as types of tasks which will contribute to obtain the lighting level according to requirement and comfortable to the users.

Sekyere used portable lux meter to assess the suitability of solar-powered LED "(Light Emitting Diod) and CFL (Compact Fluorescent Lamp) lighting systems as replacement for kerosene lanterns [20]. In this measurement, lux meter had been placed at the middle of the board in a dark room to measure the illuminance of the light that fall on the flat surface [20]. Every location was conducted three times to get the average value for the calculation of luminance flux in the study and for accuracy; the experiment were conducted three times [20]. Based on past researchers, this study would note that experiment especially with the used of sensitive tools should be conducted several times to get an average. Thus, this would aid in acquiring a more accurate result for the study and beneficial data for future usage.

Lux meter is a device that can be used to assess the illuminance at the workplace and have assisted in obtaining results for past research. Also, to get other additional information with regards to lighting especially concerning the operators; questionnaires [11], vision tests [6] and interviews could always assist. The results of light assessment techniques and tools in determining the luminous level in manufacturing plants are similar between the past researchers, thus, proving its reliability and accuracy. The aims of most research concerning lighting was observed by this study were mostly with the objective to obtain the luminance and illuminance measurement with the purpose of achieving human comfort and safety.

\section{Conclusion}

Sufficient lighting is important in the manufacturing industry due to its impact on operators' visual comfort, work performance and safety. Among physiological discomforts closely associated with insufficient lighting are eyestrain, migraine, headaches and fatigue. Insufficient lighting increases the risk of hazards to the operators in term of proneness to accidents and injuries, thus, would eventually affect the company's productivity and overall profit lost due to workers' compensations, medical costs and might as well penalties. The physical measurement of brightness is known as luminous and can be assess via equipment such as the Lux Meter and Digital Light Meter. The luminous level could be determined in accordance to the employees' comfort zone and 
also dependent on their tasks. This study suggest that lighting issues should be focused on during the early design stages of plant setup by basically locating the suitable sources of light and determining the optimum level of luminance for every tasks which would be performed by human operator. This would ensure the level of human comfort of the plant to be first satisfied prior to the production begins to run.

\section{References}

[1] P. T. Mc Cabe and W. S. Atkins, Contemporary Ergonomics, The Ergonomics Society, Taylor and Francis (2002)

[2] M. D.Cueva, A. Duran, N. Montalbo,V. Quevedo. Impact of the Source of Light to Work Performance of Inspectors in a Garment Factory, Southeast Asian Network of Ergonomics Societies Conference (SEANES) (2012)

[3] Health and Safety Executive (1987) Lighting at Work, In. Retrieved Disember 27, 2012, from website http://www.hse.gov.uk/pubns/books/hsg38.htm

[4] A.Wolska, Human Aspects of Lighting in Working Interiors, International Encyclopedia of Ergonomics and Human Factors (2006)

[5] P.R. Boyce, the Impact of Light in Buildings on Human Health, International Society of the Built Environment (ISBE) (2009)

[6] O. Untimanon, W. Pacharatrakul, K. Boonmeepong, L. Thammagarun, N. Laemon, S. Taptagaporn and V. Chongsuvivatwong. Visual Problems among Electronic and Jewelry Workers in Thailand, Journal of Occupational Health (2006)

[7] D. Fischer, Interior Lighting, IEEE Proceedings, Vol. 133, Pt. B, No. 2 (1986)

[8] "Factory Lighting in War-time", Aircraft Engineering and Aerospace Technology, Vol. 12 Iss: 11 pp. 347- 348. (1940)

[9] C. Connolly,"Lighting for industrial inspection", Sensor Review, Vol. 22 Iss: 2 pp. 106-112. (2002)

[10]K. Steemers, "The Role of Lighting in the Environmental Performance of Buildings", Facilities, Vol.11 Iss: 5 pp. 14 - 19. (1993)

[11]T. Hwang and J. T. Kim, Effects of Indoor Lighting on Occupants' Visual Comfort and Eye Health in a Green Building, International Safety of the Built Environment (ISBE), (2010)

[12]P. R. Boyce, Illumintaion, Handbook of Human Factors (2006)

[13]M. G. Helander, Design of Visual Displays, Handbook of Human Factors (1997)

[14]D. McCloy. The Queen's University of Belfast, Aircraft Engineering and Aerospace Technology, Vol. 47 Iss: 6 pp. 4 - 8. (1975)

[15]W. G. Hyzer. An Extintion-Type Photometering Techniques for Low-Light-Level Luminance Measurements in Accident Investigations, ASTM International. (1988)

[16]Putarajaya Lighting Masterplane Final Report, Survey of Existing Road and Street Lighting In Putrajaya, September 2002

[17]Digital Lux Meter Testo 545, (n.d.). In RS Components, Retrieved Disember 27, 2009 from http://uk.rs-online.com/web/p/light-meters/3276345/

[18]Lux Meter, (n.d.). Retrieved Disember $\quad 27, \quad 2009$ from www.nerc.gov.jo/RUE/InstrumentRUE/LuxMeter.pdf 
[19]E. H.W. Chan, K.S. Lam, W.S. Wong. Evaluation on indoor environment quality of dense urban residential buildings, Journal of Facilities Management, Vol. 6 Issue: 4 pp. 245 - 265. (2008)

[20]C.K.K. Sekyere, F.K. Forson, F.O. Akuffo, Technical and economic studies on lighting systems: A case for LED lanterns and CFLs in rural Ghana, Elsevier. (2012)

[21] "Market Watch 2012", The Malaysian Automotive and Supplier Industry "Malaysia's economy attains 7th position”, New Straits Times, 20th May 2011.

[22]T. Driscoll, R. Loiselle, M. Walton, G. Brady. Industrial Ligthing Safety, Can You See the Problem? IEEE. (2006) 